\title{
Hydroxyzine dihydrochloride premedication is a necessity for pediatric patients undergoing strabismus surgery: An observational prospective clinical trial
}

Fatma Ferda Kartufan ( $\nabla$ mdferdakartufan@gmail.com )

Medistanbul Hospital

Nurcan Kizilcik

Yeditepe University: Yeditepe Universitesi

Sule Ziylan

Yeditepe University: Yeditepe Universitesi

Ferdi Menda

Yeditepe University: Yeditepe Universitesi

\section{Research Article}

Keywords: Strabismus, oculocardiac reflex, premedication, hydroxyzine, midazolam

Posted Date: March 7th, 2022

DOI: https://doi.org/10.21203/rs.3.rs-1165795/v1

License: (1) (1) This work is licensed under a Creative Commons Attribution 4.0 International License.

Read Full License 


\section{Abstract}

Objective: In this single-blind, observational prospective trial we aimed to determine and compare the effect of premedication with hydroxyzine plus midazolam and midazolam alone on the incidence of Oculocardiac Reflex (OCR).

Methods: Forty-five patients divided into three groups retrospectively after surgery; according to the oral premedication before surgerys. Group $\mathrm{M}$ received $0.5 \mathrm{mg} / \mathrm{kg}$ midazolam alone, Group $\mathrm{H}$ received 0.5 $\mathrm{mg} / \mathrm{kg}$ hydroxyzine plus $0.5 \mathrm{mg} / \mathrm{kg}$ midazolam, and Group HM received $1 \mathrm{mg} / \mathrm{kg}$ hydroxyzine plus 0.5 $\mathrm{mg} / \mathrm{kg}$ midazolam. The observational part of the study was carried out prospectively during surgery. The Ramsay Sedation Scale (RSS), the heart rates (HR1: after induction of anesthesia; HR2: before retraction of orbital muscle; and HR3: right after retraction of orbital muscle), the muscles with OCR and the incidence of OCR ( $20 \%$ decrease of the HR right after the traction) were recorded and compared between the three groups.

Results: The mean HR1, HR2 and HR3 values were significantly increased $(p=0.002, p<0.001, p<, 0.001)$ and the incidence of OCR ( $p=0.004)$ was significantly decreased in the Group $H$, and in the Group HM (for all, $p<0.01)$ compared to the Group M. No statistically significant difference was found between the Group H and Group HM in terms of RSS, HR1, HR2, HR3 and the incidence of OCR (for all, p>0.05). The most common orbital muscle in which OCR occurred was the rectus medialis.

Conclusion: Premedication with a combination of 0.5 or $1 \mathrm{mg}$ hydroxyzine with $0.5 \mathrm{mg}$ midazolam significantly reduced the incidence of OCR compared to the premedication with midazolam alone.

\section{Introduction}

Strabismus is defined as any deviation of binocular alignment that can be the cause or the effect of poor binocularity (1). If left untreated timely in children, it may have dramatic consequences in their educational ability, impairing their physical and physiological performance and leading to cosmetic problems $(2,3)$. The prevalence of strabismus is reported between 2 to $4 \%$ of the world's pediatric population (4). The mainstay of the strabismus treatment is surgery. Early strabismus surgery could not only reduce damage to binocular visual function resulting from strabismus, but also facilitate the restore of visual function after surgery (5).

The oculocardiac reflex (OCR) is defined as a decrease in heart rate greater than $20 \%$ compared to the baseline following globe pressure or traction of the extraocular muscles (6). The OCR is a trigeminalvagal reflex triggered by the stimulation of the ophthalmic branch of the trigeminal nerve during strabismus surgery. Vagal stimulation reduces heart rate, and may cause sinus bradycardia, ventricular fibrillation, atrioventricular block and asystole (7). The incidence of OCR during strabismus surgery has been reported between $56 \%$ and $68 \%$ (8). The incidence of OCR decreases by age and the pediatric population is at the highest risk (6). Therefore the OCR is one of the serious challenges faced by pediatric anesthesiologists during strabismus surgery. 
It has been reported that increased anesthesia depth influences subcortical areas and prevent the development of OCR through the suppression of nociceptive and autonomic reflexes (9) and that OCR can be prevented by retrobulbar block and with anticholinergic medications (1). Several studies in the literature have investigated the effects of using various anesthetic agents in pediatric strabismus surgery on the incidence of OCR. According to the results of these studies; propofol or remifentanil anesthesia was associated with a higher incidence of OCR compared to sevoflurane and desflurane when midazolam was used as the induction agent (10); dexamethasone administered as nasal prophylaxis increased the rate of OCR (11); ketamine and midazolam showed similar effects and did not reduce the incidence of OCR (12). On the other hand, not administering neuromuscular blockers and premedication with benzodiazepine have been reported to reduce the risk of OCR by 3.64 and 3.11 times, respectively (9). In addition, atropine premedication has been reported to reduce OCR and prevents undesired effects of dysrhythmias (13). In another study, the incidence of OCR was found to be significantly lower with sevoflurane compared to midazolam (14).

Hydroxyzine dihydrochloride is an antihistamine that crosses the blood brain barrier and reduces activity in the central nervous system, and thus it can be used in premedication as a sedative to treat anxiety and tension before surgery. To our best knowledge, there is no study in the literature to evaluate the effect of hydroxyzine dihydrochloride on the incidence of OCR. In this study, we aimed to investigate the effects of premedication with hydroxyzine dihydrochloride plus midazolam on the incidence of OCR in comparison with midazolam alone.

\section{Material And Methods}

This study was designed as a single-blind, observational, prospective trial and registered with the Clinical Trials number: NCT03806270. Before the beginning, the study protocol was approved by the local ethics committee with the 09/09/2018 dated and 884 numbered decision. All participants and their parents were informed in detail about the objectives of the study and gave written informed consent. The study was conducted in accordance with the relevant ethical principles of the Declaration of Helsinki (DoH).

A total of 75 ASA I class patients, aged between 1 and 10 years, and scheduled for strabismus surgery in Yeditepe University Hospital and Yeditepe University Eye Center 2018 and 2019 were included in the study. Patients with a greater ASA status, those who were scheduled for another surgery, patients smaller than one years and older than 10 years of age, and those with a history of chronical illness, arrhythmia or glaucoma (narrow-angle) were excluded from the study. In addition, patients for whom premedication was not ordered or any medication other than used in the study was ordered in premedication were also excluded.

All surgeries were performed by the same surgeon. The most commonly preferred premedications in our anesthesiology clinic for sedation of pediatric patients include $0.5 \mathrm{mg} / \mathrm{kg}$ oral midazolam combined with hydroxyzine dihydrochloride in different doses $(0.5 \mathrm{mg} / \mathrm{kg}$ or $1 \mathrm{mg} / \mathrm{kg})$ or $0.5 \mathrm{mg} / \mathrm{kg}$ oral midazolam 
alone with cherry juice of maximum $5 \mathrm{~mL}$. In the present study, we aimed to compare the effects of these three combinations on OCR.

Patients administered midazolam alone ( $0.5 \mathrm{mg}$ with cherry juice) were assigned to Group $\mathrm{M}$, those given $0.5 \mathrm{mg}$ midazolam plus $0.5 \mathrm{mg} / \mathrm{kg}$ hydroxyzine dihydrochloride to Group $\mathrm{H}$ and patients who received 0.5 mg midazolam plus $1 \mathrm{mg} / \mathrm{kg}$ hydroxyzine dihydrochloride to Group HM.

\section{Study Sampling}

Seventy-five pediatric patients were planned to be included in this observational study based on a $20 \%$ decrease in OCR compared to the baseline value, using an effect size: $0.40, a: 0.05$ and power:0.8 values, the number of patients that should be included in each group was calculated as 25 using G power 3.0.10. However, after reaching 45 patients (15 in each group), post hoc test was done to evaluate the significance between the oral premedication utilized and the OCR occurrence, HR1, HR2, HR3 and RSS values. Because there was significance in more than one groups (between oral premedication, and OCR, oral premedication and HR2 and oral premedication and HR3), the study was completed before reaching the exact number of participants.

\section{Data Collection}

The analyzed study data included The Ramsay Sedation Score (RSS) determined preoperatively between 1 point indicating "anxious or restless or both response to stimulus" and 6 points showing "no response to stimulus"; The Heart Rate-1 (HR1) showing the lowest heart rate observed from ECG monitorization at the "time-out" check, after the anesthesia induction and before starting the surgery; The Heart Rate-2 (HR2) observed from the ECG monitor when the surgeon warned the researcher just before the traction of each orbital muscle; The Heart Rate-3 (HR3) which was the lowest rate observed from the ECG monitor within 120 seconds after each orbital muscle traction; The OCR Occurrence; and The Orbital Muscle on which traction was performed during surgery.

The anesthesiologist of the patient who ordered oral premedication for sedation before the surgery was not included in the trial. Patients' demographic data and premedications were obtained by the researcher from the patient files after the strabismus surgery, retrospectively. According to the observational setting of the trial, the participants were not randomized and no control group was enrolled.

\section{Statistical Analysis}

Data obtained in this study were statistically analyzed using the SPSS version 23.0 (SPSS, Statistical Package for Social Sciences, IBM Inc., Armonk, NY, USA) statistical software. Demographic data of the patients were expressed as mean \pm standard deviation, minimum and maximum values. Post Hoc examination was carried out with the One Way ANOVA and Chi-Square tests in order to evaluate the differences between the groups in terms of HR1, HR2, HR3, OCR and RSS. Comparison of HR1, HR2 and HR3 values between the premedication groups was made with the Independent samples $t$ test. The ChiSquare and Fisher's Exact tests were used to determine the significance of OCR incidence between the 
premedication groups and to evaluate the RSS according to the oral premedication utilized. $p<0.05$ values were considered statistically significant.

\section{Results}

A total of 45 pediatric patients who underwent strabismus surgery with premedication were included in the study with 15 patients in each group. Of all patients, 21 (46.7\%) were female and 24 (53.3\%) were male. The mean age of the patients was found as $4.2 \pm 2.6$ years. The mean height was found as $102.5 \pm 18.4 \mathrm{~cm}$ and the mean weight was measured as $17.1 \pm 8.1 \mathrm{~kg}$. Demographic data of the patients based on gender is given in Table 1.

Table 1

Demographic data of the patients based on gender

\begin{tabular}{|llll|}
\hline & $\begin{array}{l}\text { Female } \\
(\mathbf{n = 2 1})\end{array}$ & $\begin{array}{l}\text { Male } \\
(\mathbf{n = 2 4})\end{array}$ & $\begin{array}{l}\text { Total } \\
(\mathbf{n}=\mathbf{4 5})\end{array}$ \\
\hline & \multicolumn{3}{|c|}{ Mean \pm Standard Deviation } \\
\hline Age (year) & $4.3 \pm 2.4$ & $4.2 \pm 2.8$ & $4.2 \pm 2.6$ \\
\hline Height (cm) & $102.6 \pm 16.1$ & $102.5 \pm 20.5$ & $102.5 \pm 18.4$ \\
\hline Weight $(\mathbf{k g})$ & $17.6 \pm 7.6$ & $16.7 \pm 8.7$ & $17.1 \pm 8.1$ \\
\hline
\end{tabular}

The main finding of this study was that administration of premedication with both $0.5 \mathrm{mg}$ midazolam plus $0.5 \mathrm{mg} / \mathrm{kg}$ hydroxyzine and $0.5 \mathrm{mg}$ midazolam plus $1 \mathrm{mg} / \mathrm{kg}$ hydroxyzine reduced the incidence of OCR compared to $0.5 \mathrm{mg}$ midazolam alone. OCR occurred in $6(40 \%)$ patients in Group M and one (6.6\%) patient in Group H, while none of the patients in Group HM developed OCR (Figure 1). Accordingly, the incidence of OCR was statistically significantly lower in the Group H $(p=0.002)$ and the Group HM $(p=0.001)$ compared to the Group M. No statistically significant difference was found between the Group $\mathrm{H}$ and Group HM in terms of the occurrence of OCR ( $p>0.05)$.

The mean HR1 was statistically significantly higher in the Group HM compared to the Group M $(p=0.017)$. No statistically significant difference was found between the Group $\mathrm{H}$ and Group $\mathrm{M}$ and between the Group H and Group HM (both, p>0.05). The comparison of HR2 and HR3 values based on the orbital muscles was statistically significant between the Group M (n:29) and Group H (n:28) and between the Group M (n:29) and Group HM (n:30) (both, p<0.001).

The mean RSS score was statistically significantly higher in the Group HM compared to Group H $(p=0.01)$. There was no correlation between the RSS scores and the incidence of OCR. The strabismus surgeries were performed on a total of 87 orbital muscles and OCR occurred in 22 (25.3\%) muscles. Distribution of the orbital muscles in which OCR occurred is shown in Figure 2. In addition, comparison of the incidence of ORC related to the orbital muscles according to the premedication groups is shown in Table 3. 
Table 3

Distribution of the orbital muscles with OCR according to the groups

\begin{tabular}{|c|c|c|c|c|}
\hline $\begin{array}{l}\text { Premedication } \\
\text { Group }\end{array}$ & $\begin{array}{l}\text { Orbital muscles } \\
\text { with ORC } \\
(n=22)\end{array}$ & $\begin{array}{l}\text { Orbital muscles } \\
\text { operated } \\
(n=87)\end{array}$ & $\begin{array}{l}\text { Orbital muscles } \\
\text { with ORC / } \\
\text { Orbital muscles } \\
\text { operated }\end{array}$ & $\begin{array}{l}\text { Orbital muscles with } \\
\text { ORC / } \\
\text { Total muscles } \\
\text { operated }(n=87)\end{array}$ \\
\hline Group M & 15 (68.2\%) & 29 & 15 (51.72\%) & 15 (17.24\%) \\
\hline Group H & $6(27.3 \%)$ & 28 & $6(21.4 \%)$ & $6(6.90 \%)$ \\
\hline Group HM & $1(4.5 \%)$ & 30 & $1(3.3 \%)$ & 1 (1.15\%) \\
\hline Total & 22 (100\%) & 87 & $22(100 \%)$ & $22(25.3 \%)$ \\
\hline
\end{tabular}

\section{Discussion}

The OCR was described for the first time by Aschner in 1908 and is frequently encountered in pediatric strabismus surgery (12). In the present study, OCR was defined as a $20 \%$ decrease in heart rate compared to the baseline value following globe pressure. Most OCR resolves without treatment, but it may sometimes cause devastating results such as cardiac arrest and sudden death (15). The activation of OCR is also associated with non-cardiac outcomes such as syncope, hypotensive attacks, emergence agitation and gastrointestinal reflexes, including postoperative nausea and vomiting (PONV) and emergence agitation (6). The incidence of PONV following strabismus surgery can rise to $85 \%$ in the pediatric population (16).

The manipulation of the extraocular muscles is one of the most important triggers of the development of OCR. The OCR is caused by traction applied to the extraocular muscles, pressure on the globe, ocular trauma or traction on the conjunctiva. Traction applied especially on the rectus medialis has been associated with the occurrence of OCR (17). Multiple studies have reported an increased incidence of OCR with medial rectus traction compared to other ocular muscles $(18,19)$. Similarly, in our study the right and left rectus medialis were the most common muscle in which OCR occurred by $77 \%$.

It has been reported that not administering premedication before pediatric strabismus surgery is associated with a 3.11 times increase in the risk of developing OCR (9). Therefore, it is important to understand and manage OCR with proper premedication for the anesthesiologist. An effective premedication can reduce the incidence of OCR as well as PONV, length of stay, costs and workload on the healthcare staff.

In the present study, a combination of both $0.5 \mathrm{mg}$ and $1.0 \mathrm{mg}$ hydroxyzine with $0.5 \mathrm{mg}$ midazolam significantly reduced the incidence of $O C R(p=0.002$ and $p=0.001$, respectively). Many different anesthetic agents have been used to help decrease the occurrence of OCR with varying incidence. Several studies have shown that premedication with anticholinergic agents such as atropine or glycopyrrolate decreases the incidence of $\operatorname{OCR}(11,20,21)$. However, the use of atropine is controversial, because it can produce 
undesirable dysrhythmias and if it penetrates into the central nervous system, central anticholinergic syndrome may be triggered (12). On the other hand the results reported by different studies on pediatric strabismus surgery are diverse in daily practice (22). Misurya et al. demonstrated that patients receiving premedication with atropine and retrobulbar block with $2 \%$ xylocaine did not develop OCR (23). There are studies stating that ketamine was effective in reducing the incidence of OCR compared to other anesthetic drugs. Hahnenkamp et al. reported that a combination of ketamine with a volatile anesthetic may be useful for preventing OCR However, high doses of ketamine are needed in order to achieve this preventing effect (24). Oh et al. compared the incidence of OCR between ketamine and midazolam. In that study, although the occurrence of OCR was more frequent in the midazolam group, the difference was not statistically significant (12). Also, the side effects of ketamine such as hypersalivation and disturbing dreams are common. For this reason, ketamine is not the first choice in premedication (25). In another study, Abdelaziz et al. compared intranasal dexmedetomidine or intranasal midazolam and found that midazolam was associated with higher incidence of OCR, although the difference did not reach statistical significance (26). Anticholinergic drugs can cross the blood-brain barrier and cause undesirable conditions such as postoperative delirium, urinary dysfunction, skin rash, fever, and anticholinergic syndrome (27). Besides, systemic applications of anticholinergic drugs also cause ectopic beats and ventricular arrhythmias, and for this reason are not recommended for routine prophylaxis in pediatric ophthalmic surgeries (28).

In the present study, we investigated the effect of $0.5 \mathrm{mg}$ or $1 \mathrm{mg}$ hydroxyzine combined with oral midazolam and midazolam alone on the incidence of OCR for the first time in the literature and found a lower incidence of OCR with both doses of hydroxyzine.

Hydroxyzine acts by suppressing the activity of some subcortical structures such as reticular formation and the limbic system. In this way, it relieves the feeling of anxiety and reduces the emotional and somatic response to stress. It's relaxing effect on skeletal muscles, bronchodilator activity, antihistaminic, and analgesic effects are other important positive effects $(29,30)$.

It has been shown in various clinical studies that hydroxyzine also has antiemetic effects. It also strongly inhibits cutaneous and systemic anaphylaxis. Hydroxyzine is completely metabolized in the liver after rapid absorption from the gastrointestinal tract and is mainly excreted fecally. In this respect, it seems suitable for oral premedication. There is no interaction with atropine is also an important advantage for the possibility of using atropine in OCR treatment. When evaluated in these aspects, it may be thought that it may be superior to anticholinergics as premedication.

\section{Study Limitations}

The main limitation of this study is the relatively small number of patients. In addition, several other factors such as the incidence of PONV and length of stay in hospital could be studied. However, being the first in the literature to investigate the effect of premedication with hydroxyzine on the incidence of OCR 
in pediatric strabismus surgery makes this study strong and guiding for further studies to be conducted in the future.

\section{Conclusion}

Premedication with a combination of 0.5 or $1 \mathrm{mg}$ hydroxyzine with $0.5 \mathrm{mg}$ midazolam did not only sedate agitated pediatric patients before strabismus surgery, but also protect them by reducing the incidence of OCR. However, further comprehensive studies with a larger series of patients are needed to draw firm conclusions.

\section{Declarations}

\section{Trial Registry:}

This study was registered on https://clinicaltrials.gov/ with No: NCT03806270

\section{Acknowledgements:}

N/A

\section{Conflict of Interest:}

Authors did not report any conflict of interest.

\section{Financial Support:}

The study did not receive financial support.

\section{Data Availability:}

Data used in this study are included in the manuscript.

\section{References}

1. Garcia C, de Sousa A, Mendonça M, de Anderade L, Oréfice F. Prevalence of strabismus among students in Natal/RN-Brazil. Arq Bras Oftalmol. 2004;67 (5):791-794.

2. Chia A, Dirani M, Chan $Y$, et al. Prevalence of amblyopia and strabismus in young Singaporean Chinese children. Invest Ophthalmol Vis Sci. 2010;51 (7):3411-3417. 
3. Jackson S, Harrad R, Morris M, Rumsey N. The psychosocial benefits of corrective surgery for adults with strabismus. Br J Ophthalmol. 2006;90(7):883-888.

4. Agaje BG, Delelegne $D$, Abera $E$, et al. Strabismus prevalence and associated factors among pediatric patients in southern Ethiopia: a cross-sectional study. J Int Med Res. 2020;48(10):300060520964339.

5. Wan, X., Wan, L., Jiang, M., Ding, Y., Wang, Y., \& Zhang, J. (2021). A retrospective survey of strabismus surgery in a tertiary eye center in northern China, 2014-2019. BMC ophthalmology, 21(1), 40.

6. Dunville LM, Sood G, Kramer J. Oculocardiac Reflex. [Updated 2020 Jun 28]. In: StatPearls [Internet]. Treasure Island (FL): StatPearls Publishing; 2020 Jan

7. Donlon JV, Doyle DJ, Feldman MA. Anesthesia for eye, ear, nose and throat surgery. In: Miller RD, (ed.) Miller's anesthesia, Philadelphia, Churchill Livingstone 2006;2527-55.

8. Neils, D. M., Singanallur, P. S., Vasilakis, M., Wang, H., Tsung, A. J., \& Klopfenstein, J. D. (2014). Incidence and ramifications of the oculocardiac reflex during the orbitozygomatic approach: a prospective assessment. World neurosurgery, 82(6), e765-e769.

9. Aydın BG, Küçükosman G, Pişkin Ö, et al. Factors affecting oculocardiac reflex incidence in pediatric strabismus surgery: Retrospective study. JARSS 2021;29(1):58-64.

10. Choi, S. R., Park, S. W., Lee, J. H., Lee, S. C., \& Chung, C. J. (2009). Effect of different anesthetic agents on oculocardiac reflex in pediatric strabismus surgery. Journal of anesthesia, 23(4), 489-493.

11. Arnold, R. W., Jansen, S., Seelig, J. C., Glasionov, M., Biggs, R. E., \& Beerle, B. (2021). Anesthetic Impacts on the Oculocardiac Reflex: Evidence from a Large, Observational Study. Clinical ophthalmology (Auckland, N.Z.), 15, 973-981.

12. Oh A, Yun M, Kim H, Kim H. Comparison of desflurane with sevoflurane for the incidence of oculocardiac reflex in children undergoing strabismus surgery. Br J Anaesth. 2007;99:262-5.

13. Gilani, S. M., Jamil, M., Akbar, F., \& Jehangir, R. (2005). Anticholinergic premedication for prevention of oculocardiac reflex during squint surgery. Journal of Ayub Medical College, Abbottabad: JAMC, 17(4), 57-59.

14. Çeliker V, Dal D, Saricaoglu F, Başgül E, Aypar Ü. Comparison of the effects of midazolam and sevoflurane on oculocardiac reflex. Turk Anesteziyoloji ve Reanimasyon Dernegi Dergisi. 2004; (32): 367-372.

15. Ha SG, Huh J, Lee BR, Kim SH. Surgical factors affecting oculocardiac reflex during strabismus surgery. BMC Ophthalmol. 2018;18(1):103. Published 2018 Apr 19.

16. Watcha MF, Simeon RM, White PF, Stevens JL. Effect of propofol on the incidence of postoperative vomiting after strabismus surgery in pediatric outpatients. Anesthesiology. 1991;75(2):204-209.

17. Deriy L, Gerstein NS, Panikkath P et al. Cardiac Patients Requiring Emergent Noncardiac Surgery; in Essentials of Cardiac Anesthesia for Noncardiac Surgery 2019, Pages 404-452. 
18. Shakil H, Wang AP, Horth DA, Nair SS, Reddy KKV. Trigeminocardiac Reflex: Case Report and Literature Review of Intraoperative Asystole in Response to Manipulation of the Temporalis Muscle. World Neurosurg. 2019 Feb;122:424-427.

19. Başağaoğlu B, Steinberg A, Tung IT, Olorunnipa S, Maricevich RS. Oculocardiac Reflex as a Late Presentation of Orbital Floor Fracture. J Craniofac Surg. 2018 Oct;29(7):e720-e722.

20. Rahimi Varposhti M, Moradi Farsani D, Ghadimi K, Asadi M. Reduction of oculocardiac reflex with Tetracaine eye drop in strabismus surgery. Strabismus. 2019 Mar;27(1):1-5.

21. Ducloyer JB, Couret C, Magne C, Lejus-Bourdeau C, Weber M, Le Meur G, Lebranchu P. Prospective evaluation of anesthetic protocols during pediatric ophthalmic surgery. Eur J Ophthalmol. 2019 Nov;29(6):606-614.

22. Gayer S, Tutiven J. Anesthesia for pediatric ocular surgery. Ophthalmol Clin North Am 2006; 19: 26978.

23. Misurya VK, Singh SP, Kulshrestha VK. Prevention of oculocardiac reflex (O.C.R) during extraocular muscle surgery. Indian J Ophthalmol 1990; 38: 85-7.

24. Hahnenkamp K, Hönemann CW, Fischer LG, Durieux ME, Muehlendyck H, Braun U. Effect of different anaesthetic regimes on the oculocardiac reflex during paediatric strabismus surgery. Paediatr Anaesth. 2000;10(6):601-608.

25. White PF, Way WL, Trevor AJ. Ketamine its pharmacology and therapeutic uses. Anesthesiology 1982; 56: 119-36.

26. Abdelaziz HMM, Bakr RH, Kasem AA. Effect of intranasal dexmedetomidine or intranasal midazolam on prevention of emergence agitation in pediatric strabismus surgery: A randomized controlled study. Egyptian Journal of Anaesthesia. 2016; 32(3):285-291.

27. Joo J, Lee S, Lee Y. Emergence delirium is related to the invasiveness of strabismus surgery in preschool-age children. J Int Med Res 2014; 42:1311-1322.

28. Rodgers A, Cox RG. Anesthetic management for pediatric strabismus surgery: continuing professional development. Can J Anaesth 2010; 57:602-617.

29. Guaiana G, Barbui C, Cipriani A. Hydroxyzine for generalised anxiety disorder Cochrane Database Syst Rev. 2010 Dec 8;(12).

30. Bethesda (MD) LiverTox: Clinical and Research Information on Drug-Induced Liver Injury. Bethesda: National Institute of Diabetes and Digestive and Kidney Diseases; 2012.

\section{Figures}




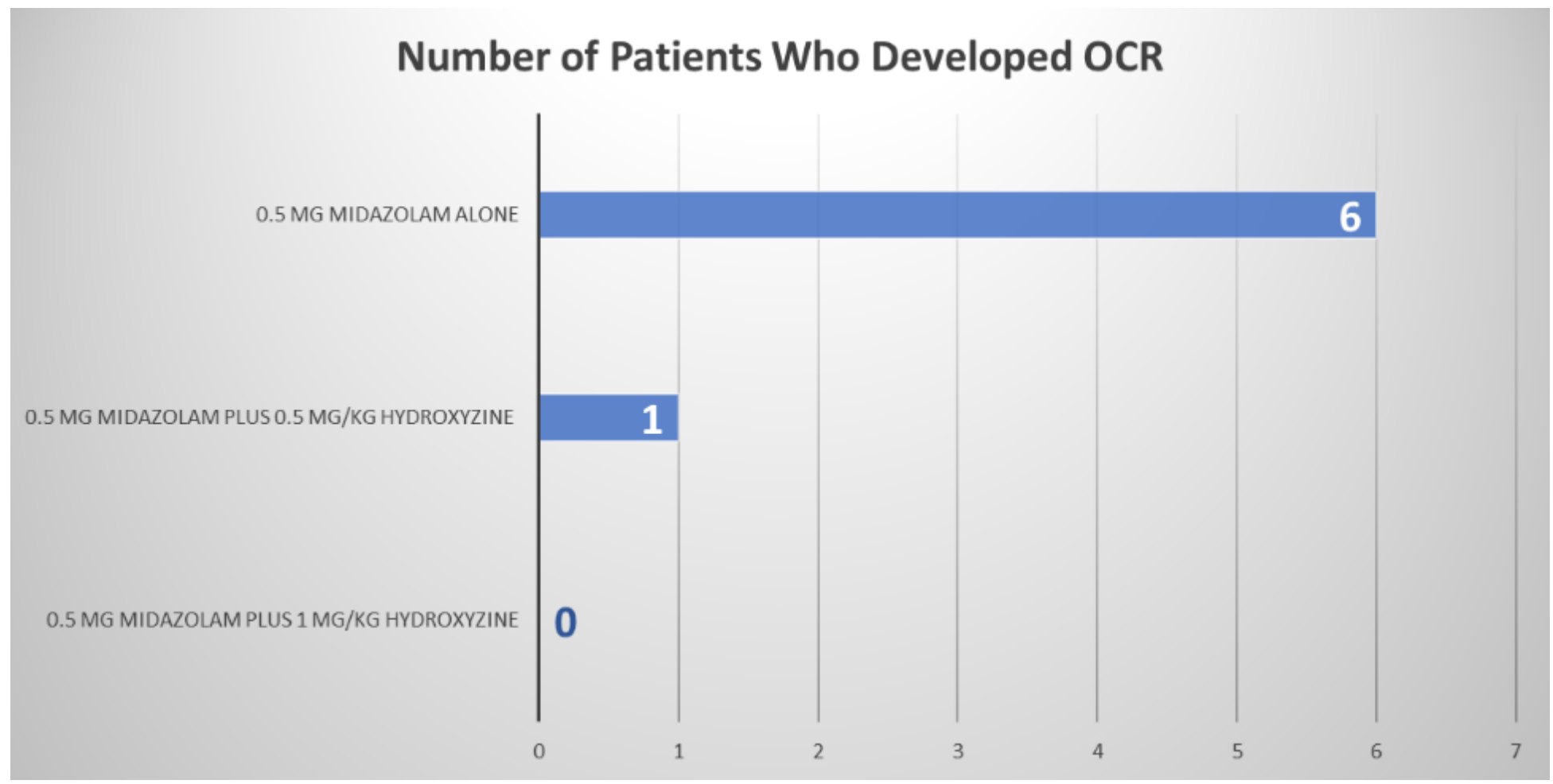

\section{Figure 1}

The incidence of OCR between the groups

\section{Distribution of Orbital Muscles}

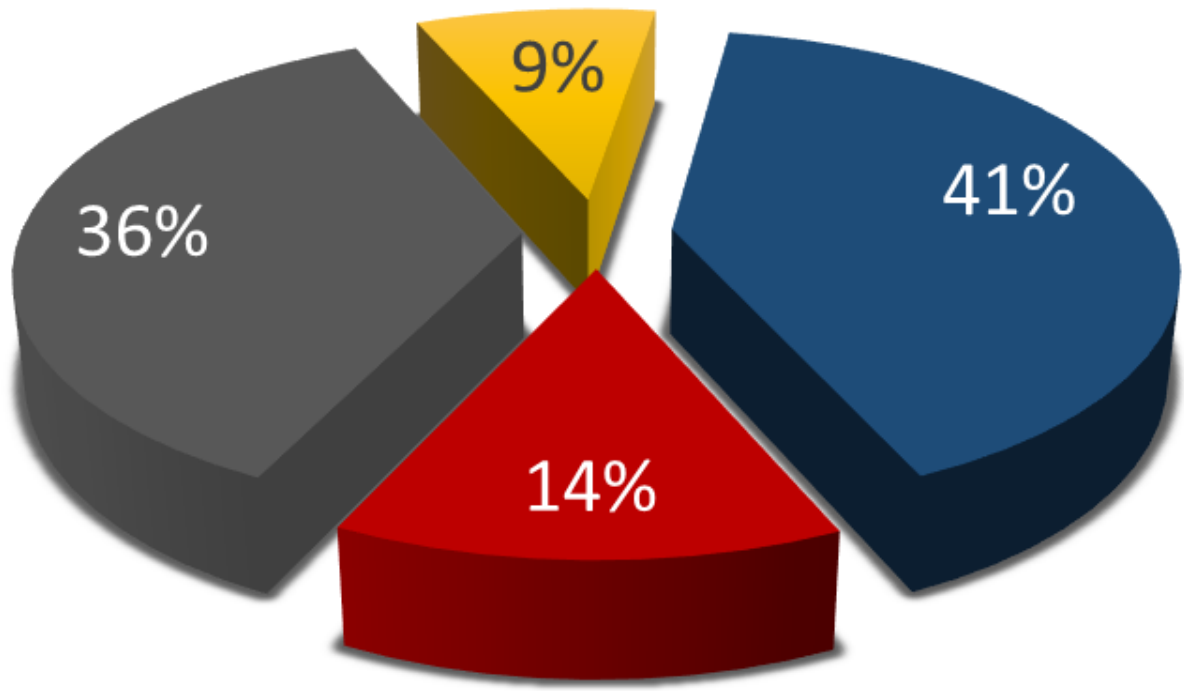

- Right Rectus Medialis $\quad$ Right Rectus Lateralis $\quad$ Left Rectus Medialis $\quad$ Left Rectus Lateralis 
Figure 2

The distribution of orbital muscles in which OCR occurred 